\title{
PUBLIC RESPONSE TO CANCER SCREENING AND DETECTION PROGRAMS
}

\author{
DETERMINANTS OF HEALTH BEHAVIOR
}

\author{
I. M. Rosenstock, Ph.D.* \\ School of Public Health, University of Michigan, Ann Arbor.
}

(Received 11 January 1963)

As A BACKDROP against which to illuminate the kinds of educational problems that will be encountered in stimulating public acceptance of cancer screening and detection programs, an analysis should be presented of the conditions under which people take action leading to the detection or prevention of diseases. Unfortunately, very little pertinent research has been done with respect to cancer screening or detection programs. The bulk of the findings that will be reported has emerged from a series of investigations on public response to tuberculosis detection programs [1] as well as public response to preventive programs in the areas of dental diseases [2], rheumatic fever [3], influenza [4], and polio [5]. One specific study of women's response to screening for cervical cancer has been made, but it is of unknown generality since the population studied was a group of female employees of the Chronic Disease Division of the Public Health Service [6].

The findings from these studies have led to the formulation of a model for explaining behavior in response to disease threat. Since the model has been spelled out in some detail in the published documents cited, its major pertinent elements will be given only briefly here. The principal components of the model that are relevant to this discussion include (1) the health motive or health threat, (2) beliefs about the utility of various courses of action in reducing the health threat and (3) conflicts among motives and potential courses of action. Other elements of the model that are less relevant here will not be discussed.

\section{The health motive or threat}

Two principal dimensions define whether a health event will become subjectively motivating or threatening. They include first, the degree to which the individual believes that he is susceptible to a given health problem or disease, and, second, the extent to which he believes that contracting such a disease or problem would have serious consequences for him. The person who fails to believe that he is likely to contract a given illness or that the illness is serious will not be motivated to take action regarding it-he must believe both. In this area of beliefs concerning susceptibility and severity, the emphasis is on the person's beliefs and not on *Associate Professor of Public Health Administration. 
objective reality. It is well known that people vary markedly in their interpretations of so-called objective reality. Moreover, the term 'severity' or 'seriousness' of illness as used here includes more than the clinical or medical severity of the illness. It may, and often does, include beliefs about consequences in areas such as family relationships, finances, and occupation. Thus, for example, an individual might regard tuberculosis as a disease which is not clinically serious but as having profound negative implications for his family, his finances, his career, and his social relationships.

In summary then, the health motive that determines whether a decision will be made to take any action, whether health related or not, consists of the degree to which the individual feels threatened by a given disease, where the threat is defined as including both the degree of perceived susceptibility to the condition, and the perceived seriousness of that condition should it occur.

It is important to consider the role that the strength of the threat plays in determining action. From the foregoing comments, it might be expected that the more susceptible an individual believes he is to a given disease and the more serious he believes that disease to be for him, the more likely he will be to take action. Unfortunately the relationship is not that simple. To be sure, at one extreme where the individual sees no threat whatever, his tendency to act will be zero. Moreover, as the intensity increases moderately, the tendency to act increases accordingly. As the intensity of threat increases still further, however, great anxiety may be aroused that interferes with adaptive action $[7,8]$.

\section{Belief about the utility of various courses of action in reducing the health threat}

In order for an individual to take some course of action relative to a real or potential health problem, he must not only feel threatened by the problem as defined above, but he must also believe that one or more courses of action are open to him which in his view would reduce the likelihood of occurrence of the disease or which would reduce the seriousness of the problem should it occur. In addition, he must believe that taking the proposed action would not in and of itself entail or lead to even greater threats than the health threat he is attempting to diminish.

With respect to a decision to accept a disease preventive, such as immunization, the individual, thus, must believe that the preventive is available to him and he must know where and how to obtain it. He must further believe that the preventive will be effective when properly administered and that the individual or agency from whom the preventive is to be obtained is competent to administer it.

A screening or diagnostic test is in some ways similar to and in some ways different from a preventive. Before a person can decide to accept a specific screening or diagnostic test such as one for cancer, he must believe that he might currently be suffering from cancer even in the absence of symptoms, or if he has symptoms, he must be aware that the symptoms might indicate the presence of cancer. He must believe that existing techniques which are available to him can detect asymptomatic as well as symptomatic disease, and he must believe that early detection of disease would improve the prognosis in his case. Finally, he must believe that the personnel and facilities available to him are competent to employ these tests.

An individual will not take a recommended action if he does not accept each of 
these beliefs about the usefulness of the action in his case. On the other hand, the acceptance of these beliefs merely constitutes a set of positive features which increase the attractiveness of the recommended action. The attractiveness of the action may be reduced by the existence of certain negative features considered below.

\section{Conflicts among motives and courses of action}

The individual's motives and various beliefs about motives and courses of action are often in conflict with each other. Behavior emerges as the resolution of such conflicts. Three kinds of conflicts may be described:

(a) An available course of action to satisfy a motive may be intrinsically frustrating.

(b) The individual may not see any course of action to satisfy an existing motive.

(c) Two motives may compete with each other for dominance.

(a) Even when a person is motivated relative to his health, a conflict may occur to influence ultimate behavior if the action he is required to take is in itself seen as unpleasant, painful, inconvenient, upsetting or expensive. Even if the person sees a course of action as potentially effective in reducing the threat, he may not take it if it conflicts with more powerful internal forces.

(b) In another and important type of conflict, the individual fails to accept the health workers' beliefs that effective means do in fact exist to prevent or ameliorate specific conditions and is, thus, unable to see any action as being effective. In this case, as well as in the case in which an effective action is seen as creating great problems for him, existing experimental evidence suggests that one of two reactions may occur. First, the individual may attempt to remove himself psychologically from the conflict situation by engaging in activities which do not satisfy his motive but are symbolically related to it [9]. Perhaps some of those who have not found a more direct means of satisfying their particular health motives concentrate on giving volunteer service in a health organization. Still further removed from the original unsolvable health problem, but, nevertheless, motivated by it may be an increasing reliance on mysticism and magic.

A second major consequence of the absence of satisfactory means for solving an important health threat is marked increase in fear or anxiety [8]. If the anxiety or fear becomes strong enough, the individual may arrive at a state in which he can no longer think objectively and behave rationally about the problem; in fact, he may even deny that it is important to him. Even if such an individual is subsequently offered a more effective means of handling the problem, he may not accept it simply because he can no longer think constructively about the problem.

(c) A third kind of conflict may occur when two motives both demand satisfaction, e.g., economic motives and motives related to health. Ordinarily, the motive having the highest importance for the individual will become dominant. Existing data based on limited observations suggest that the set of health motives taken as a whole are perhaps less potent or salient for most people than other kinds, such as motives concerning social approval. As a consequence, health-related motives may be superseded by others where the two have a potential for being aroused at the same time. Several observers have made unpublished observations that, follow- 
ing times of natural disaster, the affected population is less likely to call on physicians for routine illnesses than in normal times. This principle of the conflict of motives may be helpful in explaining why lower socioeconomic groups do not appear to be highly motivated in the health area. It may well be that in such groups, motives for food, shelter, and clothing override motives for he'alth.

It is important to note that the intensity of an existing motive to take action may be reduced if any delay occurs between the point of decision and the earliest time at which action can be taken. Since the proposed action is frequently intended to reduce the probability of occurrence of some serious event, each day, hour, or moment that the individual remains safe in the absence of action may tend to reduce his conviction that the action is needed. Suppose a person decides to seek polio vaccination because he believes he is susceptible to the disease, but for some reason he postpones the actual vaccination by several days. With passing time, as he observes that he does not in fact contract the disease, he may become less convinced that he is susceptible.

This fact may explain why, as GrifFiths and KNUTSON [10] and HochBaUM [11] have noted, the objectives of a communication are more likely to be achieved when the recommended action is readily available for quick and immediate delivery. Where the recommended action is not ready for quick and immediate delivery, communications are less likely to be effective.

Before completing discussion of the behavioral model, it should be noted that frequently behavior which appears to be based on the individual's desire to avoid or overcome some health condition may in reality be determined by forces which have little or nothing to do with his concern about his health. Thus, in some circumstances, a particular health action may be taken or avoided directly as a means of satisfying the needs for conformity. Groups exert subtle but very powerful influences on their members to conform to the group norms and standards of opinion and behavior [12-15]. The pressure to conform may be so powerful that it leads individuals on occasion to deny their own senses [16]. It is, thus, likely that many of the individual's health decisions are a consequence of his dependence on groups. It is not improbable that many parents bring their children for regular pediatric examinations less because of a concern with health than to conform with the norms established by the groups of friends, neighbors, and relatives. Evidence of such social effects has been obtained, for example, in studies on the acceptance of tuberculosis screening [1] and on the acceptance of polio vaccination [5].

\section{A P PLICATION OF BEHAVIORAL MODEL TO CANCER}

DETECTION

It is not simple to apply these principles to the problem confronting the profession in cancer detection, since as indicated, no specific generalizable study has been made that links these principles to cancer detection. However, suggestive data are available from studies supported by the American Cancer Society. In 1948, the Survey Research Center of the University of Michigan conducted a National Sample Survey of 1244 persons for the American Cancer Society [17]. The sludy covered a variety of topics but included data on public knowledge of cancer, attitudes and beliefs about the disease and medical health practices. In 1955 the A. C. S. repeated 
the initial survey on 6928 respondents. Some of the findings of the studies that appear to relate to the behavioral model will be reported [18].

\section{Do members of the public believe they are susceptible to cancer?}

No direct answer to this question can be given. The 1955 A. C. S. survey showed that in response to a question on opinions concerning susceptibility to cancer, 29 per cent of the public believed that all ages are susceptible. One might imagine that these 29 per cent accept their own susceptibility to the disease. In addition, it might be expected that those people who select their own age as being most susceptible to cancer would accept their own personal susceptibility. While there is some merit in this argument, it is not adequate. Evidence from some of the studies cited earlier demonstrates that a health belief may be accepted as applicable to people in general, but not to oneself. Some respondents might be saying in effect 'anybody can get cancer, but it won't happen to me'. In the absence of a definitive study, it should not be assumed that all or most people accept their susceptibility to cancer merely because many highly educated people of our acquaintance feel susceptible.

\section{Is cancer seen as a serious disease?}

Evidence on this score is somewhat better. In both the 1948 and 1955 surveys it was learned that about 80 per cent of the public believes cancer to be one of the most dangerous diseases. Other studies support this finding in general. Moreover, while detailed data are lacking, common knowledge suggests that a great many people regard cancer as a most serious, painful, expensive and often fatal condition.

Pending more definitive information on the cancer threat, it may be hypothesized that a considerable number of people feel threatened by the disease and consequently are in a state of motivation to take action to reduce the threat. While there is no way of knowing what proportion of the public feels so threatened, the degree of threat where it exists would appear to be more than minimal. Research may show that many of those who feel threatened are so highly motivated that they do not always behave rationally about the cancer problem. Such over-motivated or anxious people may avoid experiences which might teach them more of the facts about cancer. Indirect evidence bears on this conclusion. In 1955, 40 per cent of the public were unable to name a single one of the seven so widely publicized cancer danger signals. While there was a definite relationship between knowledge of danger signals and educational attainment, 21 per cent of all college graduates could not correctly name a single danger signal, while an additional 17 per cent could name only one. In the face of the intensive efforts to communicate this knowledge to the public such a response may be regarded as poor and it is consistent with the hypothesis that the threat of cancer arouses maladaptive anxiety in many people.

3. What does the public believe about detectability and curability of cancer, and the channels through which to obtain detection tests?

In both the 1948 and 1955 studies, more than 80 per cent of the respondents reported a belief that a person could have cancer without knowing anything was 
wrong. This compares very well with HochBAUM's finding that "more than 80 per cent (of the respondents studied) stated that chest X-rays could detect tuberculosis in a person before he notices any signs or symptoms of the disease" [1]. However, HochBAum went on to ask a number of indirect questions on the same topic and discovered that 30 per cent of the correctly informed group failed to accept this information as relevant to themselves. That is, they believed that people can have tuberculosis without symptoms, but they gave evidence that in their own cases they would rely on the appearance of symptoms to detect tuberculosis. If HochBaum's findings were applicable to the cancer situation, we would find that about 60 per cent and not 85 per cent of the population would both accept the knowledge that people can have cancer without symptoms and would also apply it in their own cases.

Does the public know where and how to obtain an examination for cancer? While no evidence on this matter is available, we do have some data on where members of the public actually go.

The 1948 survey showed that 14 per cent of the sample responded "Yes" to the question, "Were you ever examined to see whether or not you had cancer?"; in 1955,30 per cent so indicated.*

Of the 1955 respondents reporting having had a cancer examination, 65 per cent were examined by their regular doctors, while 34 per cent were examined in clinics. Clearly the great majority seek examinations by their regular doctors, a tendency encouraged by the American Cancer Society.

No data are available on opinions about the validity of detection methods; however, opinions were elicited about the competence of medical personnel to detect cancer. In 1948, 44 per cent of the respondents believed that the family doctor can recognize cancer or that he can recognize it in some cases. In 1955 the proportion had risen to 61 per cent. The proportion believing that the family doctor would need special training to diagnose cancer dropped from 49 per cent to 28 per cent. In the two studies, 6 per cent (1948) and 10 per cent (1955) said they did not know whether the family doctor could recognize cancer without special training. In short, 6 out of 10 people (in 1955) believed their family physician could sometimes or always recognize cancer, while a sizeable proportion lacked complete confidence in the doctor's ability.

There is evidence that a majority of people believe that there are curative treatments for cancer patients; the proportion exhibiting this belief rose 6 per cent over the 7-yr interval between the studies, to a figure of 66 per cent. Over 30 per cent of the public on the other hand is either doubtful about the possibility of cure or do not know of any curative procedure.

It would thus appear that while the proportions of people exhibiting beliefs in the detectability and curability of cancer are increasing, there remain sizeable segments of the public, perhaps as high as $35-40$ per cent, who do not accept one or the other or both of these beliefs. Increasing numbers of people are confident that their regular doctors can recognize cancer but a sizeable group lacks such confidence.

*It should not be thought that the 1955 figure necessarily represents any increase, since in theory it includes an accumulation of persons examined at any time in the past. Thus the 14 per cent who reported examination for cancer prior to 1948 are presumably included among those reporting such examinations prior to 1955 . 
4. Are cancer detection and treatment procedures seen as unpleasant, painful, inconvenient, and expensive?

No specific information is available to answer this question but indirect evidence suggests that cancer treatment is likely to engender considerable anxiety in many people. It is known that the prospect of surgery arouses considerable anxiety in many people and 63 per cent of those who are able to name any cancer treatment at all mention surgery. Obviously the evidence in this area is most inadequate.

\section{NEEDED RESEARCH}

What can be summarized thus far about the readiness of the American public to accept cancer screening and detection programs? An answer may be attempted by reference to four prototypes: (1) a group that is insufficiently threatened by cancer; (2) a group that is sufficiently threatened and also sees an appropriate and feasible course of action to reduce the threat; (3) a group that is threatened but does not accept any remedial action as feasible; and (4) a group that is extremely threatened.

\section{Insufficient motivation}

We simply do not know what proportion of the public fails to exhibit a combination of beliefs in their own susceptibility to cancer and beliefs in the seriousness of cancer should it occur. Before systematic educational goals and programs can be established, it will be necessary to determine the scope of this problem. For this unmotivated or unthreatened group, it is probably that the usual mass media channels and methods of communication will not be adequate to alter beliefs in any significant degree. This seems true if only because there exists a group whose motives have not been influenced by these methods to date. It may be that the relevant beliefs in adults can only be modified through the utilization of social pressures.

2. Sufficient motivation accompanied by the acceptance of current remedial methods

With a group that does accept its own susceptibility to a serious discasc and also exhibits the desired combination of beliefs in the detectability and curability of cancer by reasonably convenient methods, there would seem to be no particular educational problem. This group in all probability is already following recommended courses of action and will probably continue to do so. The data presented limit the potential size of this group to $50-60$ per cent of the 1955 public, but in all probability, the actual figure is considerably lower. With respect to other health situations it has been suggested that at any given moment, no more than 25 per cent of the public stands ready to take a single specific action voluntarily to prevent or detect a given disease [19].

\section{Sufficient motivation and the failure to accept a proposed course of action}

In theory, there should be little problem in educating those who are sufficiently 
threatened by cancer but either lack confidence that it is detectable or curable or who believe that detection and treatment methods are painful, inconvenient or expensive. Presumably, all that should be needed to stimulate recommended behavior in this group is to provide them with fairly simple data which fill in informational gaps. And undoubtedly, there exists a group for whom such simple solutions would be sufficient. Unfortunately, there must also exist a group which has been informed of the facts but does not believe one or more of them.

At present, only speculation is possible about why people fail to accept certain technical information. In this speculation, one must first ask whether there is a rational basis for failure to accept what professionals regard as the facts. While many cancers may be detectable in early stages, are there not some which are not detectable in early stages? What hopeful information can be given to people whose parents or friends had previously contracted leukemia, or cancer of the esophagus or the stomach? Similar arguments can be made with respect to treatment. While trcatment doubtless prolongs life materially in some cases, it clearly does not in others. An individual probably does not look at his likelihood of survival in terms of statistics. Probably he believes that he has an all or none chance to survive in a given situation, and in his own case, this belief is correct.

\section{Extreme threat}

There is little available evidence on why some people will reject even the demonstrated facts about cancer detection and cure. However, the consequences of the rejection are better understood. As indicated earlier, one of the most profound of these consequences is to increase anxiety to such a level that the person becomes even less educable in the future even as better treatments are developed.

What can one do to re-educate people who reject knowledge of cancer detection and cancer cures on irrational grounds as well as those who are highly anxious about cancer? As medical science and technology improves, there will doubtless be an accompanying change in public opinion and knowledge, but for the present such people are probably largely lost in any attempt to stimulate public acceptance of cancer detection programs.

This problem may be less difficult to solve if efforts to protect against the ravages of cancer are not restricted only to those people who explicitly seek such protection. In the context of the development of the categorical programs in the chronic diseases, public health workers may have committed an important psychological error by demanding that people learn to recognize and respond to each of several sets of symptoms in different ways. The public has been advised to seek diabetes tests under one set of circumstances, to seek cancer examinations under other circumstances and to be screened for tuberculosis under any and all circumstances. This fragmented approach poses several problems. In the first place. it demands a level of sophistication and knowledge about physiology and medicine that a great many people may simply not have. In the second place, it places on the layman certain responsibilities which he should perhaps not have for deciding what sort of examination or treatment his physician should prescribe or even for deciding what type of specialist to visit. In the third place, each program appeal loses people who are not concerned with the particular disease being considered. If it is true 
that in general, only one person in four is ready to seek a particular preventive or detection test at any given time, then each categorical appeal must be directed to four people to reach one. But, what of the other three who are lost to the particular program? While they may not be interested in the given program, are they uninterested in all health programs? It seems doubtful. Surely one or two or all three of the remainder have some interest in a variety of medical and health problems to which appeals could be directed.

But how can a wide variety of health concerns be tapped by a single health appeal? Two possible answers present themselves. The first would be to urge multiphasic screening at special screening centers, with provision for adequate referral and follow-up. Unfortunately, however desirable such a procedure may be in general, it may have little current application in cancer control since so few cancer detection tests appear to meet the usual requirements for screening tests. Generally, the tests are not susceptible of administration or interpretation by nonprofessionals; they are not for the most part simple to perform and with certain exceptions, they are not inexpensive.

It would thus appear that the most practical way of combining appeals to take various health actions in a single message would be to urge regular medical checkups even in the absence of symptoms. This, of course, has been urged by some agencies, notably, the American Cancer Society. However, widespread success in persuading people to obtain check-ups will probably not be obtained unless certain problems can be overcome. A first problem relates to the sincerity and intensity of the health worker's efforts to stimulate the public to go to their doctors even in the absence of symptoms. The traditional emphasis on observing and responding to specific symptoms may in and of itself detract from the strength of any such general appeal to obtain regular check-ups. It may also seem to many laymen that the injunction to see his doctor is frequently delivered in moralistic tones and with not very great conviction on the part of the professional. It is as if seeing one's doctor regularly is somehow good for the soul if nobody thinks it will be particularly good for the body. If this feeling prevails, can we expect people to take professional appeals seriously? Another problem that may currently limit the effectiveness of appeals to obtain general medical check-ups concerns the patient's opinions about the kind of check-up he will receive from his physician. Does he see his physician as sympathetic to the preventive check-up concept or does the physician act as if he were too busy with sick people to waste time on well people? Does the doctor fail to perform certain tests and examinations which have been cited to the patient as components of a reasonably complete physical examination? In a recent study of almost 600 doctors made for the American Cancer Society by the National Opinion Research Center some indirect evidence is presented which bears on the question [20]. While a third of the specialists interviewed reported giving physical examinations lasting $1 \mathrm{hr}$ or longer, only one non-specialist in five gives an examination of that duration. The median time reported by GPs was $30 \mathrm{~min}$ per examination, including a so-called complete medical history. Of all physicians, including specialists, 58 per cent report taking less than $45 \mathrm{~min}$ to do a general physical examination; almost a quarter report spending less than $30 \mathrm{~min}$ on such an examination. The sophisticated layman may wonder whether an adequate medical history as well as a reasonably comprehensive check-up can be completed 
in $30 \mathrm{~min}$, or less. Surely we cannot hope to obtain and sustain adequate public response to our injunctions to obtain check-ups if physicians do not give general check-ups. The medical profession needs to know more about how its members practice medicine and it may need first to persuade its membership of the value of comprehensive general check-ups before it can hope to persuade the lay public.

Finally, current ignorance about why some people currently obtain regular checkups constitutes a problem that must be overcome before we can plan fully to increase public acceptance. The research cited earlier throws light on people's response to specific health threats in terms of their acceptance or rejection of specific preventives and tests that have been offered them. It does not materially improve understanding of what motivates people to seek general check-ups on their own initiative. Why do certain individuals periodically go to their doctors to request a check-up? Indeed, what do they understand the term 'check-up' to mean? Have they had particular recent experiences which make a check-up seem desirable? Are they concerned with specific diseases, or with health and disease in general? Are they truly without symptoms or do they experience minor symptoms which they do not report? Are they influenced by what they read and hear, and if so, what information influences them and how? Do they go to the doctor for reasons that have little to do with health such as conforming to some real or imagined social norm? Answers to questions such as these may suggest effective approaches to use in working with people who do not currently seek regular preventive check-ups.

\section{Recommendations}

This paper is as much an outline of unanswered questions as it is a presentation of findings. That fact alone suggests the need for studies as a prerequisite to planning systematic educational programs. In the light of present ignorance, it seems appropriate to recommend a two phase research program oriented toward $(a)$ obtaining needed facts and $(b)$ experimenting with action programs to utilize these facts to increase program effectiveness. The following outline merely summarizes some of the factors that need additional study.

(a) Fact finding phase.

1. To what extent do different members of the public accept their own susceptibility to cancer; and to what extent, and in what ways, do they see it as a serious disease? How many people exhibit extreme anxiety about the cancer threat?

2. To what extent do different members of the public believe that early cancer is detectable and curable through methods, agencies and persons available to them? What do they believe about the convenience, discomfort and expense of such tests and treatments?

3. Under what conditions do people seek general medical check-ups? What does the term 'general medical check-up' mean to people?

4. What have been people's experiences in seeking such check-up?

5. To what extent do various members of the medical profession accept the value of general medical check-ups?

6. How frequent, comprehensive and valid are the examinations they perform?

(b) Action phase. On the basis of answers to these questions it should be possible to design public education programs which will be built around and thus 
will appeal to public concerns and interests in the health area generally. The medical society, the voluntary agency, citizens' groups and the official agency have important roles to play in accomplishing this objective.

Answers to the research questions should also permit the development of professional education programs oriented toward increasing professional interest, knowledge and skills in the area of disease detection, and health maintenance. Again, the medical society, the voluntary agency, and the official health agency have useful roles in accomplishing these objectives.

Progressive specialization in medicine may be quite justified on professional and technical grounds. Similarly, the proliferation of the individual categorical health agencies and institutions may also have a rational basis. However, these developments may have had unfortunate implications for public education. New educational approaches are needed if the man on the street no longer knows which doctor to see, and when, for which symptoms. Attempts to stimulate greater public participation in health maintenance programs may be more successful if practices are reoriented in a way that lifts the burden of medical decision from the shoulders of the layman and places it firmly on the shoulders of the medical profession.

But the profession must think carefully before making the decision to encourage comprehensive periodic check-ups on a broad basis. They must ask whether greatly increased public demands for such medical services could be satisfied in the light of current limitations in personnel, training, and facilities. Lest we increase public demand and anxiety for services that do not exist, steps must be taken to assure that needed services will be available.

\section{REFERENCES}

1. Hochbaum, G. M.: Public participation in medical screening programs: a sociopsychological study, Publ. publ. Hlth Serv., Wash. No. 572, 1958.

2. Kfoetes, S. S. : An analysis of some determinants for seeking dental care. Public Health Service, Washington, D.C. In preparation.

3. HeinzelmanN, F.: Determinants of prophylaxis behaviour with respect to rheumatic fever. J. Hlth hum. Behavior. 3:73, 1962.

4. Rosenstock, I. M., Hochbaum, G. M., Leventhal, H. et al: The impact of Asian influenza on community life: a study in five cities, Publ. publ. Hlth Serv., Wash. No. 776, 1960.

5. Rosfnstnck, I. M., Derryperry, M. and Carrigfr, B. K.: Why people fail to seek poliomyelitis vaccination, Publ. Hlth Rep., Wash. 74, 98, 1959.

6. Flach, E. G.: Participation in case finding program for cervical cancer, Administrative Report, Cancer Control Program, U.S. Public Health Service, Washington, D.C.

7. JANIS, I. L. and FESHBACK, S. : Effects of fear-arousing communication, J. abnorm. soc. Psychol. 48, 78, 1953.

8. Millerm, N. E. : Experimental studies of conflict, in Personality and the Behaviour Disorders, Fd. by Hinst, J. McV. Chap. XIV, Ronald Press, New York, 1944.

9. Lewin, K.: A Dynamic Theory of Personality, McGraw-Hill, New York, 1935.

10. Griffiths, W. and Knutson, A. L.: The role of the mass media in public health, Amer. J. publ. Hlth 50:515. 1960.

11. Hochbaum, G. M.: Modern theories of communication, Children 7, 13, 1960.

12. Festinger. L. et al.: Theory of experiment in social communications. Ann Arbor Research Center for Group Dynamics, Institute for Social Research, University of Michigan, 1950.

13. Festinger, L., Schachter, S. and Back, K. Social Pressures in Informal Groups, Harper, New York, 1950.

14. Hochbaum, G. M.: The relationship between group members' self-confidence and their reactions to group pressures to uniformity. Amer. sociol. Rev. 19, 678, 1954. 
15. Lewin, K.: Group decision and social change, in Readings in Social Psychology, Ed. by Newcomb, T. M. and Hartley, E. L. p. 330. Henry Holt, New York, 1947.

16. Asch, S. E.: Effects of group pressure upon the modification and distortion of judgments, in Groups, Leadership, and Men. Ed. by Guetzkow, H., Carnegie Press, Pittsburgh, 1951.

17. Survey Research Center, University of Michigan: The American public discuss cancer and the American Cancer Society, Administrative Report, Ann Arbor, Michigan, December 1948.

18. HoRn, D. et al.: Public opinion on cancer and the American Cancer Society, Administrative Report, New York, April 1953.

19. Rosenstock, I. M., Hochbaum, G. M. and Kegeles, S. S.: Determinants of health behavior. Presented at the Golden Anniversary White House Conference on Children and Youth, 1960.

20. National Opinion Research Center, University of Chichgo: Interview study of A.C.S. Professional education program, Administrative Report No. 73, Jan. 1960. 